Volodymyr A. Voskoboinick ${ }^{1}$, D.S., Associate Professor, Leading Scientist ORCID ID 0000-0003-2161-6923 e-mail: vlad.vsk@gmail.com

Oleksandr A. Voskoboinyk ${ }^{1}, \mathrm{PhD}$, Senior Research Associate e-mail: alexandr.vsk@gmail.com

Dmytro I. Cherniy ${ }^{2}, \mathrm{PhD}$, Associate Professor, Principle Investigator e-mail: Dmytro.Cherniy@gmail.com

${ }^{1}$ Institute of Hydromechanics of the NASU, Kyiv, Ukraine

${ }^{2}$ Institute of Telecommunications and Global Information Space of the NASU, Kyiv, Ukraine

\title{
THE MODELING OF DIFFERENT SCALE HYDROLOGIC PROCESSES IN AQUATORIES
}

\begin{abstract}
The results of mathematical and physical modeling of global and local hydrological processes in the water area are presented. By the method of mathematical modeling revealed variability of large-scale circulatory flow and mass transfer in a water-restricted area with complex obstacles.

In laboratory conditions, by experimental methods, in the hydrodynamic tray, on the channel and the laboratory stand, detected of local hydrodynamic processes and mass transfer around local obstacles - three-row fuel burner rafts. Mechanisms of formation of erosion and transfer of the soil near and within the single and group structures of the grillages located on the laundering sandy bottom of the channel are revealed.
\end{abstract}

Key words: razversk; vortex structure; erozed soil

\section{В.А. Воскобійник ${ }^{1}$, О.А. Воскобойник ${ }^{1}$, Д.І. Черній ${ }^{2}$}

${ }^{1}$ Інститут гідромеханіки НАН України, м. Київ, Україна

${ }^{2}$ Інститут телекомунікацій і глобального інформаційного простору НАН України, м. Київ, Україна

\section{МОДЕЛЮВАННЯ РІЗНОМАСШТАБНИХ ГУДРОЛОГІЧНИХ ПРОЦЕСІВ В АКВАТОРІї}

Анотація. Наведено результати математичного та фізичного моделювання глобальних та локальних гідрологічних процесів в акваторії. Методом математичного моделювання виявлено мінливість великомасштабних ииркуляційних течій та масоперенос в акваторії із складною гранищею, за наявності великомасштабних перешкод.

Експериментальними методами в лабораторних умовах в гідродинамічному лотку, каналі та лабораторному стенді виявлено зони, які знаходяться під інтенсивним гідродинамічним впливом, особливості локальних гідродинамічних прочесів та масопереносу навколо локальних перешкод трирядних пальних ростверків. Виявлено механізми формування розмивів $i$ намивів трунту поблизу $i$ усередині одиночних $i$ групових конструкиій ростверків, які розтамовані на розмивному піщаному дні каналу.

Ключові слова: ростверк; вихрова структура; розмив трунту

(C) V.A. Voskoboinick, O.A. Voskoboinyk, D.I. Cherniy, 2019 


\section{Вступ}

Зміни будь-яких зовнішніх умов завжди впливають на ефективність господарської діяльності в регіоні. Особливо, коли зміни умов виникають як наслідки техногенного впливу або природних катаклізмів, які самі мають регіональний масштаб. Виникає потреба як в оперативному прогнозі, так і в довготривалому прогнозуванні. Значною мірою це стосується діяльності, пов'язаної з використанням водних акваторій. Найбільшу потребу в прогнозі еволюції таких процесів, як поширення забруднень на водній поверхні, масоперенос (з урахуванням забруднень) в обмежених акваторіях під впливом змін гідрологічних i атмосферних умов відчувають служби, покликані оперативно попереджати розвиток природних i техногенних катастроф та зменшувати / запобігати їх впливу на навколишнє середовище. Таких прогнозів потребують гідрометслужби, служби із запобігання та подолання наслідків надзвичайних ситуацій, установи - проектанти гідротехнічних споруд, мостобудівники, будівники технологічних споруд, лоцманська служба та ін. Найбільш важливими факторами для оперативного реагування $\epsilon$ визначення тенденцій розвитку інтенсивного процесу для оцінки можливостей попереджувальних і рятувальних заходів.

Проблеми, які виникають в акваторіях, мають як різні за масштабами причини виникнення, так і різні масштаби проявів. На прикладі акваторії протоки, яка поєднує Азовське та Чорне море, розглянуто окремі частини гідрологічних проблем - загальну зміну структури течії та масоперенос (донних грунтів та поверхневих забруднень), що виникли як наслідок техногенного впливу - побудови великомасштабних гідротехнічних та інженерних споруд в акваторії. Це дамба, яка суттєво змінила лінію узбережжя та мостовий перехід, що побудовано в зоні підвищеного гідродинамічного впливу. Наслідки вищеназваних техногенних впливів здатні призвести до якісних змін в структурі течії та вплинути на масоперенос донних грунтів, небезпечний в зоні фарватеру протоки. Мета роботи - визначення механізмів утворення цих впливів та можливих наслідків, за умови їх довготривалості. Метод досліджень математичне моделювання та фізичний лабораторний експеримент.

\section{Постановки задач та методи досліджень}

Розглядається течія в мілководній акваторії (рис. 1), яка являє собою широкий канал 3 перешкодою та 3 криволінійною формою лінії узбережжя (рис. 2). Глибина каналу вважається малою та слабозмінною. Течія вважається в'язкою та плоскопаралельною (рис. 3). Враховуючи те, що при дослідженні течій в акваторіях, як правило, головний інтерес представляє осереднена по товщині шару [1] поверхнева та придонна швидкість, було використано математичну модель шаруватих течій [2-4]. Течія, яка розглядається, описується рівняннями Нав'є-Стокса, тому модель заснована на аналітичному рішенні рівнянь Нав'є-Стокса (1) для окремого випадку шаруватих течій, з урахуванням конвективних доданків та нестаціонарності (для якої, при зміні параметрів, течія Хіл-Шоу є окремим випадком).

$$
\frac{\partial \vec{V}}{\partial t}+\nabla\left(\frac{1}{2} \vec{V}^{2}+\frac{p}{\rho}+U\right)-\vec{V} \times(\nabla \times \vec{V})=\frac{\mu}{\rho} \Delta \vec{V}
$$




$$
\nabla \vec{V}=0
$$

Задача зводиться до визначення плоскопаралельної течії в криволінійному каналі квазіпостійної глибини. До того ж вважається, що загальна течія в акваторії вже сформована, із врахуванням впливу різних рівнів моря на вході та виході із акваторії протоки та з врахуванням впливу вітрових хвиль.

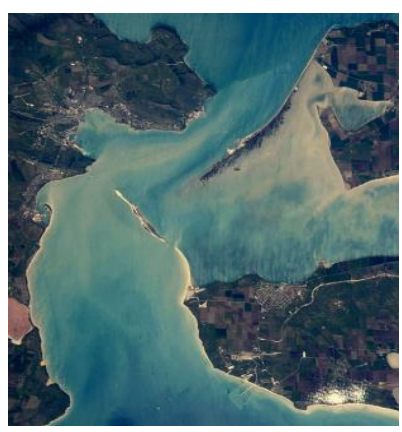

Рис. 1 - Фото акваторії із супутника

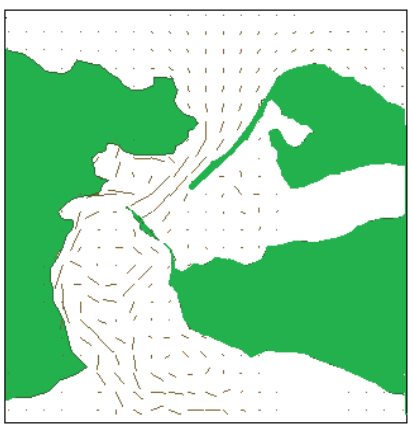

Рис. 2 - Схема течії в плоскому каналі з перешкодою

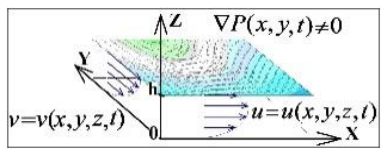

Рис. 3 - Схема течії в шарі

\section{Особливості загальної течії в акваторії}

Для визначення особливостей загальної структури течії в акваторії, разом із математичним моделюванням, було застосовано фізичне моделювання на лабораторному стенді (модель акваторії протоки у вигляді криволінійного каналу з постійною глибиною) та у гідродинамічному лотку. Враховуючи те, що швидкість у локальних частинах акваторії може досягати 1 м/сек, число Рейнольдса, визначене по глибині, вважається Red $=\mathrm{Uh} / v>10^{6}$. Наведене нижче порівняння космічних фотознімків, модельних експериментів та результатів математичного моделювання демонструє якісне співпадіння спостережуваних полів швидкості, осереднених по глибині акваторії, що підтверджує коректність зроблених припущень.

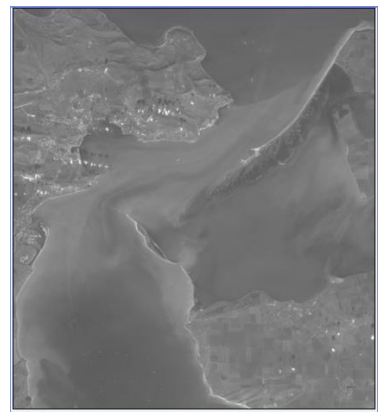

Рис. 4 - Космічне фото (Google maps)

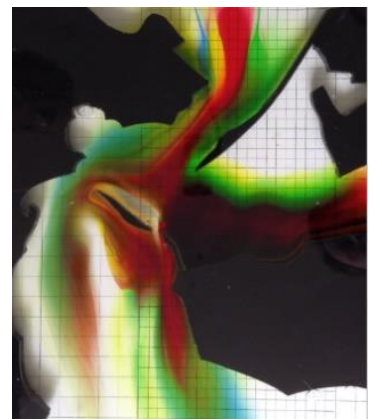

Рис. 5 - Результати експерименту

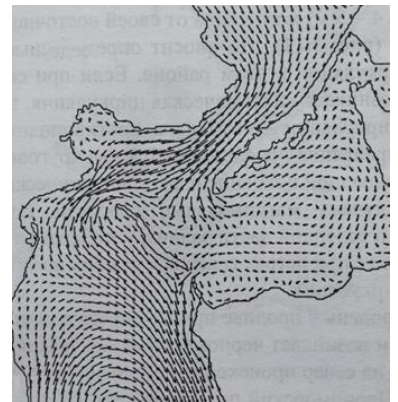

Рис. 6 - Результати матмоделювання [1]

Представлені на рис. 5-6 результати лабораторного та математичного моделювання [1] демонструють добре співпадіння зі спостережуваною 3 космосу структурою течії в акваторії (рис. 4). Варто звернути увагу на 
мінливість структури течії в акваторії (рис. 7), яка спостерігається при зміні вхідних умов, що підтверджено лабораторним експериментом (рис. 8) та математичним моделюванням (рис. 9).

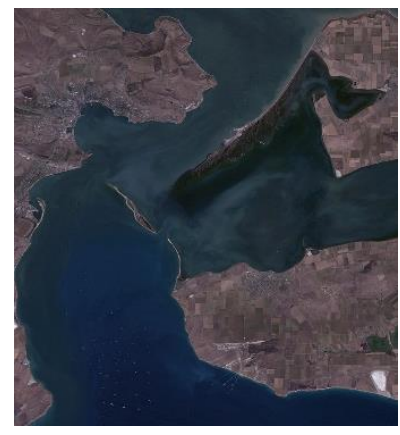

Рис. 7 - Космічне фото (Google maps)

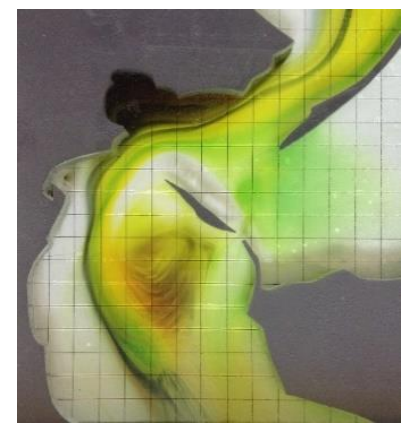

Рис. 8 - Експеримент на стенді

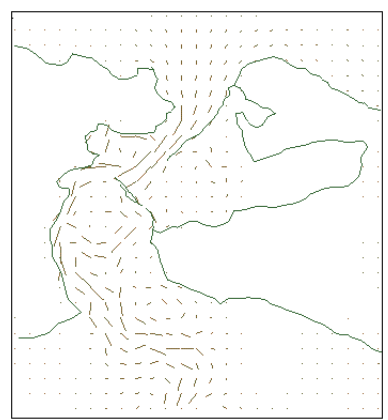

Рис. 9 - Матмоделювання $[2,5,6]$

Ефективність застосування математичних моделей (побудованих на основі методу інтегральних рівнянь $[2,5,6])$ для прогнозування переносу забруднень по водній поверхні можливо оцінити із порівняння рис. 7-9.

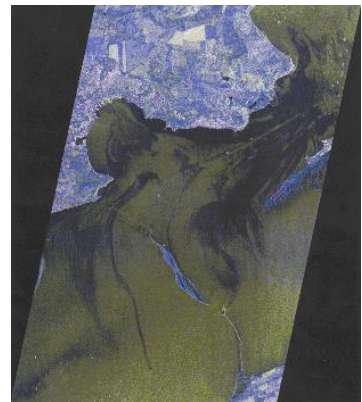

Рис. 10 - Космічне фото (TerraSAR-X. 16.11.2007)

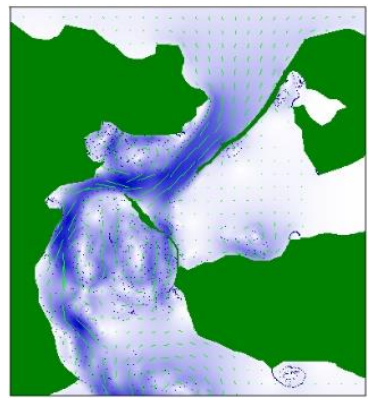

Рис. 11 - Прогнозування розповсюдження забруднень через 100 годин

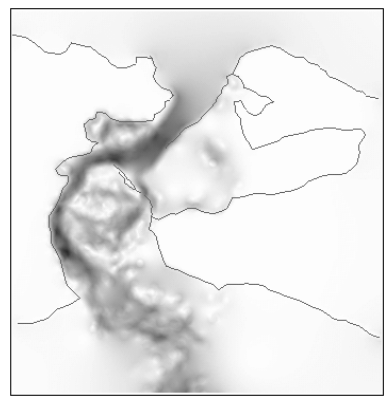

Рис. 12 - Матмоделювання $[2,5,6]$

Мінливість структури течії в акваторії, при зміні вхідних умов на вході в акваторію, підтверджено даними метеослужб Азово-Чорноморського басейну.

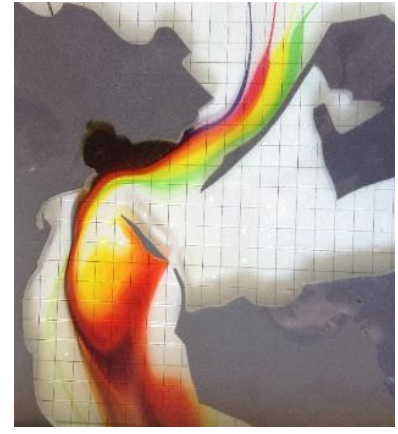

Рис. 13 - Експеримент на лабораторному стенді

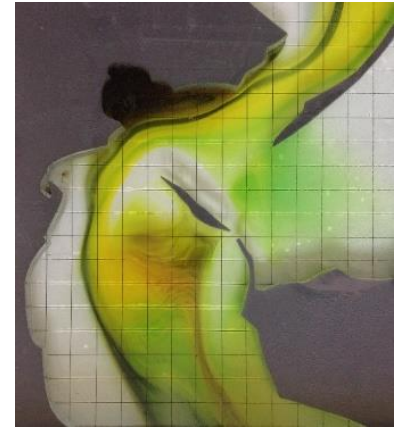

Рис. 14 - Експеримент на лабораторному стенді

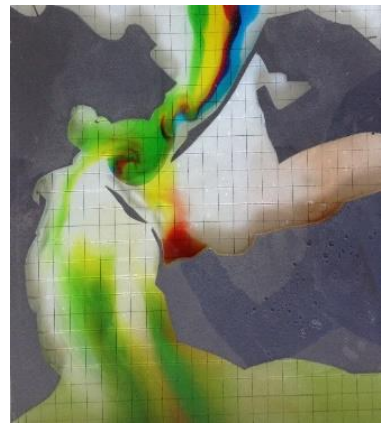

Рис. 15 - Експеримент на лабораторному стенді 
Експериментальне моделювання на лабораторному стенді також підтверджує суттєву залежність течій від параметрів на вході в акваторію (рис. 8, рис. 13-16).

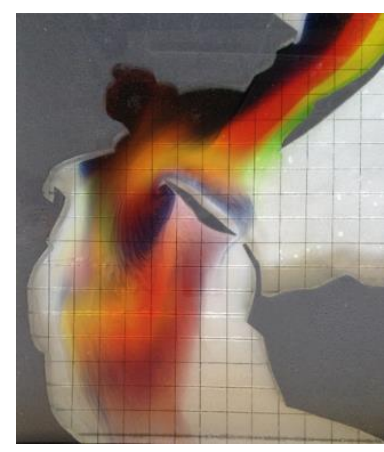

Рис. 16 - Експеримент на лабораторному стенді

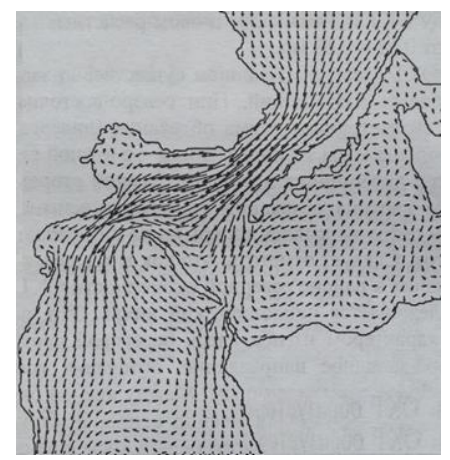

Рис. 17 - Матмоделювання [1]

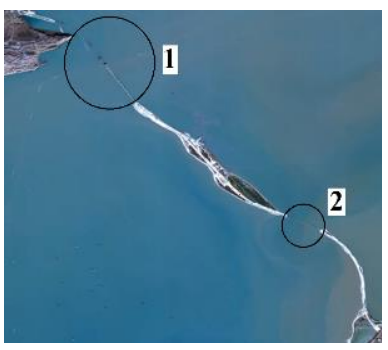

Рис. 18 - Космічне фото (Google maps)

Результати фізичного та математичного моделювання при різних вхідних даних засвідчують (рис. 16, 17), що підвищення швидкості спостерігається у проміжках між кінцівками острова-перешкоди та материковою частиною протоки, це зони 1) та 2) (рис. 18). При цьому у визначених зонах середня по глибині обчислена швидкість, а також та, що спостерігається (як в експерименті, так і при натурних вимірюваннях [1]), завжди суттєво вища, ніж в інших частинах акваторії. В окремих, локалізованих, частинах акваторії осереднена швидкість течії може наближатися до величини 1 м/сек. Доцільно звернути увагу на те, що у цих зонах 1) та 2) встановлено гідротехнічні конструкції (опори мостового переходу через протоку, рис. 18), які перешкоджають вільній течії. Тому виникає типова природня проблема гідродинамічної взаємодії з перешкодою, яка супроводжується переносом грунтів під впливом придонних течій та впливом масопереносу на зміну характеристик фарватеру. Враховуючи те, що придонна течія впливає на конструкції та споруди, які встановлені на донному грунті, доцільно розглянути вплив перешкод (наприклад, опор мосту) на масоперенос та зміну поверхні дна, що викликається гідродинамічним впливом.

\section{Локальні зони підвищеного гідродинамічного впливу}

Значна кількість гідродинамічних, гідрологічних та інженерних проблем виникає саме тоді, коли погано обтічна перешкода встановлюється на розмивній та нерозмивній поверхні, над якою протікає потік рідини. У безпосередній близькості до області спряження перешкоди та обтічної поверхні виникають градієнти тиску, які обумовлені наявністю перешкоди. Перед перешкодою примежовий шар над поверхнею дна русла або прибережної поверхні (ламінарний або турбулентний) знаходиться в області несприятливого градієнту тиску, що викликає його тривимірний відрив. У відривній області зароджується та розвивається система вихорів, які витягуються навколо основи погано обтічного тіла вздовж контуру, що схожий на підкову $[8,9]$. Так, під час обтікання мостових опор в області їх перетину 
з русловим дном утворюється складний вихровий рух, який обумовлює розмив грунту поблизу опор (рис. 19).

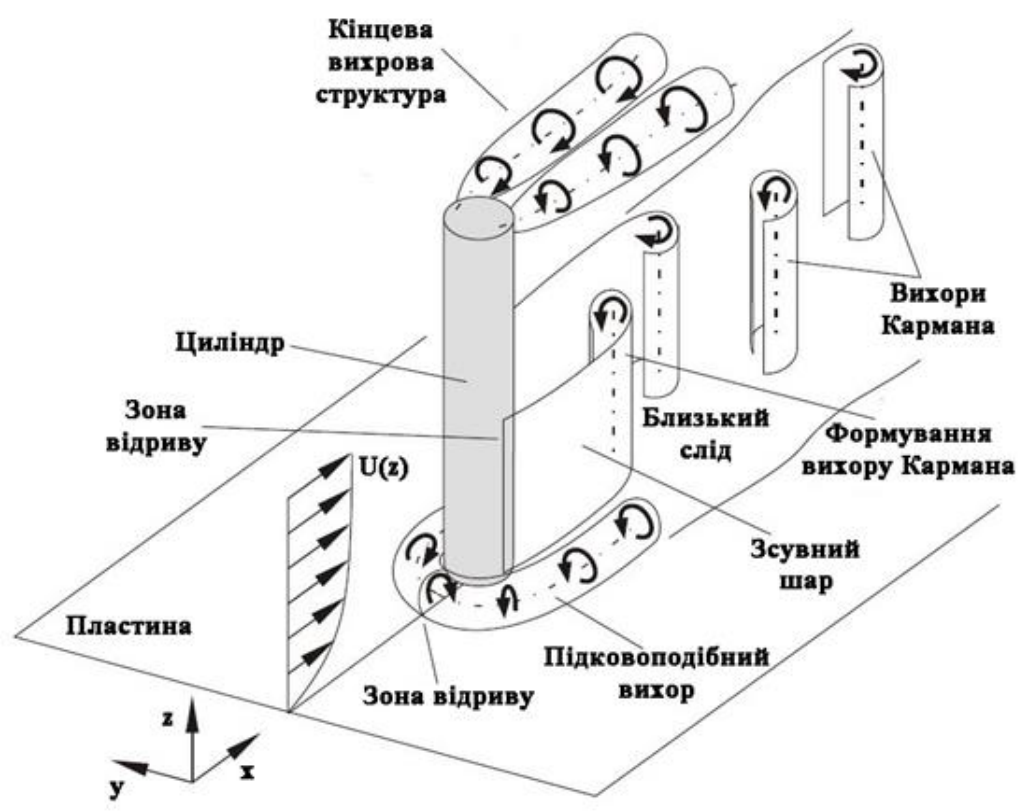

Рис. 19 - Структура вихрових течій навколо перешкоди, встановленої на пластині

Глибина розмиву становить одну 3 основних характеристик як під час проектування мостових переходів, так і під час їх експлуатації. Незалежно від форми мостової опори основним механізмом, який керує формуванням та розвитком отвору розмиву, є підковоподібна вихрова система, що утворюється біля основи опори. Стан та характеристики потоку впливають на форму та розмір вихрових систем. Серед основних факторів, які формують процес ерозії грунту поблизу мостових опор та виступів і визначають глибину локального розмиву, треба відмітити наступні: це глибина потоку, швидкість течії, ширина та форма опори, довжина опори та їі кут розташування відносно напрямку течії, розмір та градація матеріалу грунту, конфігурація дна русла та деякі інші $[10,11]$. Групування опор призводить до зміни глибини локального розмиву, що обумовлено взаємним впливом вихрової течії навколо окремих опор, які формують групову конструкцію. В залежності від місцезнаходження, конструкції опор та режиму їх обтікання змінюються кінематичні та динамічні характеристики підковоподібних, бокових і слідових вихорів, а також їх інтенсивність дії на ерозію грунту, який прилягає до опор $[10,12]$. Неоднорідність і нестаціонарність вихрової та струменевої течії поблизу і усередині групових конструкцій опор гідротехнічних споруд i поруч 3 прибережною лінією складної геометрії обумовлює проведення чисельного і фізичного моделювання механізмів і процесів вихореутворення, переносу грунту, зміни придонного та прибережного рельєфу та інших гідродинамічних i гідрологічних характеристик. Виникає важливе завдання - визначення впливу загромадження або звуження потоку на гідрологічні характеристики руслових та прибережних течій. 


\section{Лабораторне моделювання гідрологічних процесів}

Фізичне моделювання гідрологічних процесів, які відбуваються під час обтікання перешкод, що знаходяться на розмивному грунті, проводилось в лабораторних умовах. В якості перешкод було використано трирядний пальний ростверк, конструкцію якого часто використовують у мостобудівній практиці, опорах бурових конструкцій, вітряків та інших гідротехнічних споруд, які обтікаються потоком. Експериментальні дослідження впливу моделей мостових опор на локальний розмив грунту та структуру донної поверхні проводилися в гідродинамічному каналі, який мав довжину робочої ділянки близько 14 м, ширину -1.5 м та глибину -0.65 м. На відстані 8 м від початку робочої ділянки досліджувались одиночний трирядний ростверк, вісь якого знаходилася вздовж поздовжньої осі каналу, або три ростверки, які розташовувалися в ряд (рис. 20). Ці моделі мостових опор були засипані просіяним кварцовим піском на висоту близько 0.3 м від дна каналу. У дослідах пісок формувався у вигляді плаского дна. Довжина одиночного ростверку становила 0.6 м, ширина -0.1 м, а висота -0.2 м. Він складався із 31 циліндричної палі діаметром $\mathrm{d}=0.027 \mathrm{~m}$, які розташовувались у три ряди в шаховому порядку (рис. 20). Моделі інших трьох ростверків в три рази меншого масштабу мали діаметр циліндричної сваї близько 0.01 м. Відстань між осями моделей мостових переходів складала 0.31 м. Середній діаметр зерен кварцового піску $-\mathrm{d}_{50}=0.35 \cdot 10^{-3} \mathrm{M}$.

Глибина потоку мінялась від 0.17 м до 0.34 м, а середня по глибині швидкість - від $0.15 \mathrm{~m} / \mathrm{c}$ до $0.6 \mathrm{~m} / \mathrm{c}$. Для цих параметрів течії та розмірів ростверків числа Рейнольдса $\operatorname{Re}_{\mathrm{x}}=\mathrm{Ux} / v=(12-48) \cdot 10^{5}, \operatorname{Re}_{\mathrm{d}}=\mathrm{Ud} / v=(1.5-16.2) \cdot 10^{3}$ i числа Фруда $\mathrm{Fr}=\mathrm{U} / \sqrt{ }(\mathrm{gH})=(0.08-0.47)$, де $\mathrm{x}-$ поздовжня відстань у напрямку потоку від початку піщаного дна каналу до першої центральної палі ростверку; $v$ - коефіцієнт кінематичної в'язкості води; g - прискорення вільного падіння; Н - глибина потоку.

Експерименти проводилися за допомогою візуалізації течії та вимірів гідродинамічних і гідрологічних параметрів, зокрема полів швидкості, тиску, розмиву та намиву грунту. Візуалізацію було проведено за допомогою введення у потік різнокольорових барвників і чорнил. Траекторії руху кольорових барвників і особливості вихрової та струменевої течії реєстрували за допомогою цифрових відеокамер і фотоапаратів. Картини візуалізації оброблялися та аналізувалися на спеціально створеній комп'ютерній станції за відповідними програмами і алгоритмами. Поле швидкості вимірювалося за допомогою термоанемометрів, мікровертушок, трубок Піто-Прандтля, п’єзорезистивних датчиків динамічного тиску, які розташовувалися на добре обтічних державках у координатних пристроях. Поле тиску вимірювалося мініатюрними п'єзорезистивними та п'єзокерамічними датчиками тиску i пульсацій тиску, які було встановлено врівень 3 обтічною поверхнею тіл обтікання та розмивною поверхнею грунту, коли спостерігався сталий розмив грунту поблизу циліндричних паль ростверку. Розмив грунту вимірювався у процесі розмиву за допомогою спеціально спроектованих та виготовлених п'єзорезистивних і п'єзокерамічних датчиків, які за допомогою тастерів i державок або під своєю вагою занурювалися в отвір розмиву та реєстрували часовий процес утворення розмиву. Після проведення дослідів на розмивному грунті топологію дна каналу вимірювали за допомогою трьох координатних 
пристроїв, в яких закріплювалися мініатюрні п’єзокерамічні датчики пульсацій тиску. Акустичний імпеданс цих датчиків різко змінювався у момент дотику датчику до грунту, координати датчиків реєструвалися у протоколах дослідів, з наступною обробкою на комп'ютері, з послідовним аналізом із застосуванням спеціального програмного забезпечення. Таким чином, вимірювалися геометричні параметри та форма отворів і намивів розмивного грунту поблизу моделей ростверків і на дні каналу. Всі засоби вимірювань атестувалися, калібрувалися та проходили метрологічну повірку і мали відповідні паспортні дані.

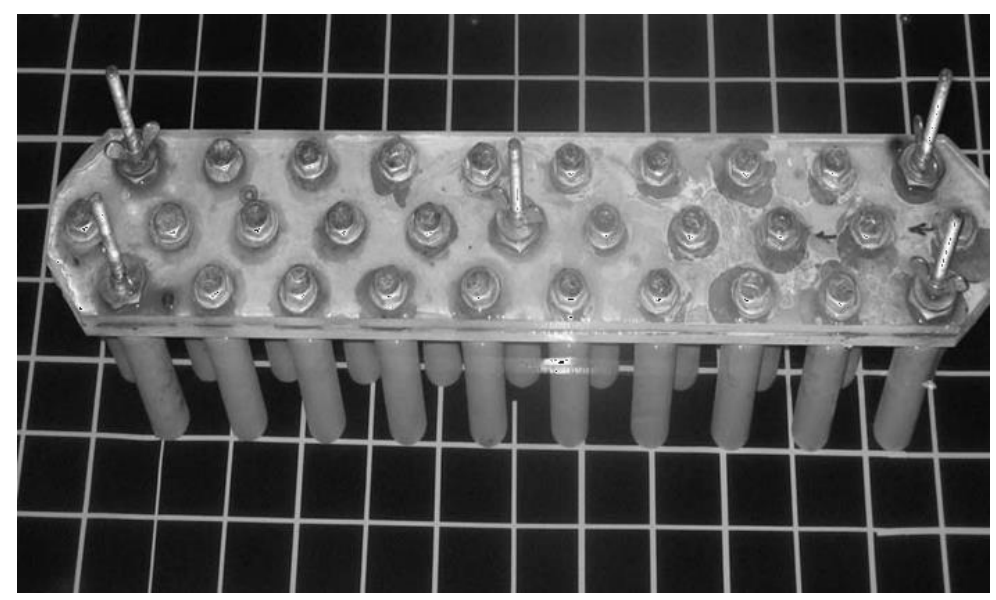

Рис. 20 - Модель трирядного пального ростверку

\section{Результати досліджень}

Результати візуалізації течії поблизу трирядних циліндричних пальних ростверків показали, що поблизу паль формується складна вихрова та струменева течія з генеруванням підковоподібних вихрових структур у місці спряження паль $з$ дном каналу, слідових вихорів за кормовими частинами паль, відривних течій перед палями і на їх обтічних поверхнях, струменевих потоків між рядами паль. Ці вихрові структури та струменеві течії формують розмиви та намиви грунту поблизу трирядних ростверків і в сліді за ними. Більш детально результати візуальних досліджень наведено у роботах [13-15].

Вимірювання полів швидкості та тиску на нерозмивній і розмивній поверхні дали можливість визначити кінематичні і динамічні характеристики вихрових $\mathrm{i}$ струменевих течій, зареєструвати місця генерації великомасштабних когерентних вихрових структур, їх особливості формування та еволюції. Визначено інтегральні та спектральні характеристики спряженої течії, полів швидкості та тиску, основні параметри яких наведено у роботах [16-18].

У результаті дії набігаючого потоку на трирядний ростверк і підковоподібних вихрових структур, які генеруються у місці спряження конструкції ростверку 3 дном каналу, а також слідових вихорів у кормі обтічних паль, на поверхні піщаного грунту утворюються розмиви та намиви грунту, що проілюстровано на рис. 21. Перед трирядною пальною конструкцією утворюється глобальний розмив грунту, а перед окремими циліндричними палями - локальні розмиви (рис. 21a). У середній частині ростверку спостерігається намив грунту, 
а у кормовій його частині знову з'являється розмив грунту, через пористість конструкції ростверку. Розміри та форма ромиву і намиву грунту залежать від чисел Рейнольдса і Фруда, зернистості піску та форми паль. Так, для чисел Рейнольдса $\operatorname{Rex}=3 \cdot 10^{6}$ i Фруда $\mathrm{Fr}=0.18$ та зернистості піску, яким вкрито дно вимірювального каналу, глибина глобального розмиву, який зображено на рис. 21a, складає 0.8 ширини ростверку, а глибина локального розмиву перед передніми палями складає 0.2d. Намив піску у середній частині трирядного ростверку складає близько 0.3 його ширини.

Розташування трьох пальних ростверків в ряд на розмивному грунті каналу призводить до зміни структури розмиву грунту i форми рифелів, які утворюються на піщаному дні каналу, що показано на рис. 21б. Між ростверками та в їх сліді рифелі набувають більшого масштабу і розмив грунту в їх впадинах збільшується. Позаду ростверків форма і масштаби розмиву та намиву грунту відрізняється від тих, що мають місце між рядами ростверків та перед ними у непорушеному потоці, що добре видно на рис. 21б. Треба відмітити, що вплив ростверків та їх групування на рельєф розмивного дна каналу спостерігається на відстані (3-5) довжин ростверків в залежності від режиму течії. Зі збільшенням чисел Рейнольдса і Фруда зміна рельєфу дна відбувається на більшій відстані.

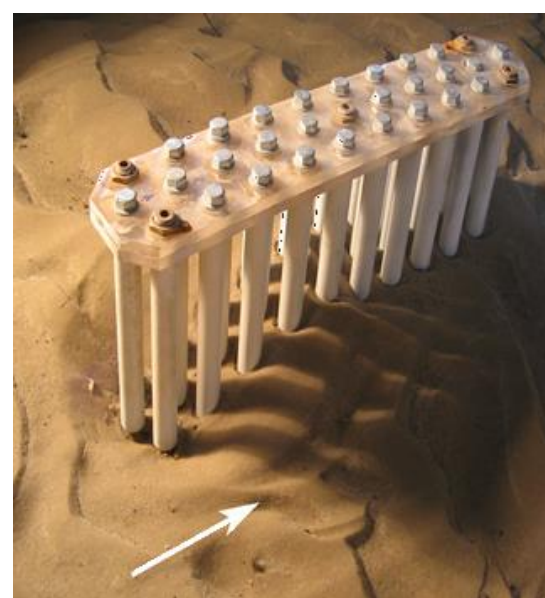

a)

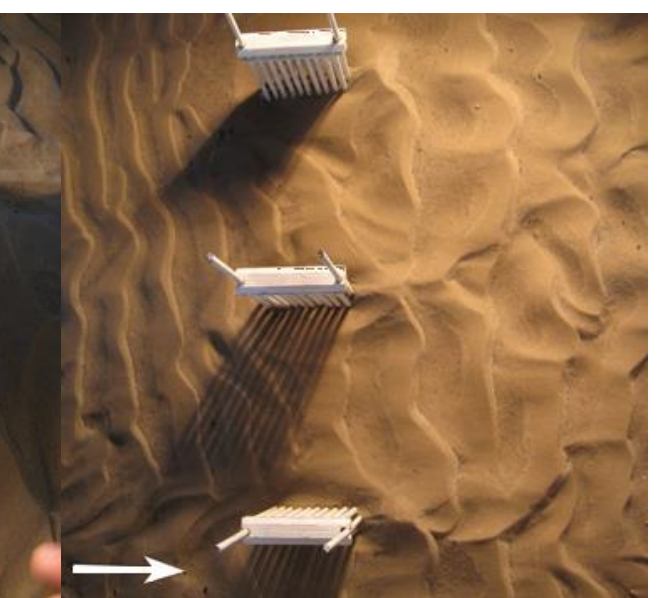

б)

Рис. 21 - Розмив і намив грунту поблизу одиночного трирядного циліндричного пального ростверку (а) та поблизу групи трирядних ростверків (б)

\section{Висновки}

Результати досліджень показали, що загромадження потоку погано обтічними тілами, зокрема трирядними циліндричними ростверками, суттєво змінює гідрологію руслової течії.

Показано, що поблизу трирядного ростверку генеруються підковоподібні вихрові структури, слідові вихори, струменеві течії. Ці гідродинамічні явища викликають розмиви та намиви грунту поблизу гідротехнічних споруд, призводять до переносу грунту у руслових потоках. Масштаб впливу залежить від форми і розміру споруд, режимів течії і структури грунту.

Визначено, що перед трирядним циліндричним пальним ростверком утворюються глобальні та локальні розмиви грунту, намиви його на бічних 
частинах ростверку і серед паль серединного перерізу ростверку та у його ближньому сліді. Розташування ростверків у ряд викликає руйнування рельєфу дна розмивного грунту як поблизу ростверків, так і в їх сліді. Установлено, що в залежності від режимів течії зміна рельєфу дна відбувається на більшій відстані від багатопальної конструкції зі збільшенням чисел Рейнольдса і Фруда. Вплив локальних конструкцій типу ростверків та їх групування на топологію розмивного дна каналу спостерігається на відстані (3-5) характерних довжин ростверків в залежності від режиму течії. Зі збільшенням чисел Рейнольдса i Фруда зміна рельєфу дна відбувається на більшій відстані. Враховуючи те, що довжина ростверку порівнянна із шириною мостового переходу, геометричний розмір зони, де помітні тенденції до розмиву грунтів та масопереносу, буде досягати 3-5 характерних ширин мостового переходу.

Таким чином, інженерні конструкції та споруди, характерна висота яких порівнянна із глибиною їх встановлення та інтервал їх встановлення на грунті $\epsilon$ порівнянним з їх характерним розміром, здатні впливати на масоперенос піщаних донних грунтів та викликати суттєві зміни рельєфу дна в мілководній акваторії. Даний факт потребує уваги гідротехнічних служб, які відповідають за безпеку фарватеру, та уваги інженерних служб, які відповідають за міцність та стійкість інженерних споруд.

\section{СПИСОК ЛІТРАТУРИ}

1. Иванов В.А. Математическое моделирование динамических процессов в зоне море суша. / В.А. Иванов, В.В. Фомин // Севастополь, НВЦ «ЕКОСІ-Гідрофізика»-2008, 363 с. 2. Черний Д.И. Математическая модель течения в мелководной акватории. / Д.И. Черний // Вісник Харківського національного університету імені В.Н. Каразіна Серія «Мат. моделювання. Інформаційні технології. Автоматизовані системи управління», Вип. 29, Харків, 2016, С. 78-86.

3. Черний Д.И. Экспериментальное и математическое моделирование слоистых течений в плоском канале. / Д.И. Черний, А.А. Воскобойник, В.А. Воскобойник // Тези науково-практичної конференції «Комп’ютерна гідромеханіка», м. Київ, 29-30 вересня 2016 р., Інститут гідромеханіки НАН України, С. 68-69.

4. Kordas O. A study on mathematical short-term modelling of environmental pollutant transport by sea currents: The Lagrangian approach / O. Kordas, A. Gourjii, E. Nikiforovich, D. Cherniy // Journal of Environmental Accounting and Management. - 2017. - Vol.5, N 2. p. 87-104 (DOI: 10.5890/JEAM.2017.06.002).

5. Довгий С.А. Метод сингулярних интегральных уравнений и вычислительные технологии. / С.А. Довгий, И.К. Лифанов, Д.И. Черний // К.: Издательство «Юстон» $2016,380 \mathrm{c}$.

6. Довгий С.О. Алгоритми методу дискретних особливостей для обчислювальних технологій. / С.О. Довгий, С.І. Ляшко, Д.І. Черній // Кибернетика и системный анализ. 2017, №6, C. 147-159.

7. Cherniy D. The Vortex Model of a Viscid Wall's Layer // IUTAM Symposium on "Vortex Dynamics: Formations, Structure and Function" / D. Cherniy, S. Dovgiy, V. Meleshko // Abstract Book, March 10(Sun)-14(Thu), 2013, Centennial Hall, Kyushu University School of Medicine, Fukuoka, Japan, pp. 126-127.

8. Guan D. Characterization of horseshoe vortex in a developing scour hole at a cylindrical bridge pier / D. Guan, Y.-M. Chiew, M. Wei, S.-C. Hsieh // Intern. J. Sedim. Res. - 2019. Vol. 34, № 2. - P. 118-124.

9. Koken M. Coherent structures at different contraction ratios caused by two spill-through abutments / M. Koken // J. Hydraul. Res. - 2018. - Vol. 56, № 3. - P. 324-332. 
10. Ettema R. Field complexity and design estimation of pier-scour depth: Sixty years since Laursen and Toch / R. Ettema, G. Constantinescu, B.W. Melville // J. Hydraul. Eng. - 2017. Vol. 143, № 3. - P. 03117006-1-14.

11. Baghbadorani D.A. Prediction of current-induced local scour around complex piers: Review, revisit, and integration / D.A. Baghbadorani, B. Ataie-Ashtiani, A.Beheshti [et al] // Coastal Eng. - 2018. - Vol. 133, № 3. - P. 43-58.

12. Yang Y. Evolution of hydrodynamic characteristics with scour hole developing around a pile group / Y. Yang, M. Qi, J. Li, X. Ma // Water. - 2018. - Vol. 10, № 11. - P. 1632-1-21. 13. Воскобойник А.А. Визуализация сопряженного обтекания групповой мостовой опоры / А.А. Воскобойник, А.В. Воскобойник, В.А. Воскобойник // Вісник Донецького Університету, Сер. А: Природничі науки. - 2008. - Вип. 1. - С. 219-227.

14. Воскобійник А.В. Особливості вихрового руху у спряженій течії між групою паль трирядної мостової опори / А.В. Воскобійник, В.А. Воскобійник, О.А. Воскобойник [та ін.] // Прикладна гідромеханіка. - 2009. - Т. 11, № 2. - С. 16-29.

15. Воскобійник А.В. Спряжене обтікання трирядного пального ростверку на пласкій поверхні. Частина 1. Формування підковоподібних вихорів / А.В. Воскобійник, В.А. Воскобійник, О.А. Воскобойник // Прикладна гідромеханіка. - 2008. - Т. 10, № 3. C. 28-39.

16. Воскобійник А.В. Спряжене обтікання трирядного пального ростверку на пласкій поверхні. Частина 2. Просторово-часові кореляції та спектри / А.В. Воскобійник, В.А. Воскобійник, О.А. Воскобойник // Прикладна гідромеханіка. - 2008. - Т. 10, № 4. C. $13-25$.

17. Voskobijnyk A.V. Feature of the vortex and the jet flows around and inside the three-row pile group / A.V. Voskobijnyk, V.A. Voskoboinick, O.A. Voskoboinyk [et al.] // Proc. 8th International Conference on Scour and Erosion (ICSE 2016) 12-15 September 2016. Oxford, UK, 2016. - P. 897-903.

18. Voskoboinick V.A., Voskoboinick A.V., Areshkovych O.O., Voskoboinyk O.A. Pressure fluctuations on the scour surface before prismatic pier / V.A. Voskoboinick, A.V. Voskoboinick, O.O. Areshkovych, O.A. Voskoboinyk // Proc. 8th International Conference on Scour and Erosion (ICSE 2016) 12-15 September 2016. - Oxford, UK, 2016. - P. 905-910.

Стаття надійшла до редакиї 13.02.2019 і прийнята до друку після рецензування 05.03.2019

\section{REFERENCES (TRANSLATED AND TRANSLITERATED)}

1. Ivanov, V. A., \& Fomin, V. V. (2008). Mathematical modeling of dynamic processes in the sea - land. Sevastopol: National Exhibition Center "EKOSI-Gidrofizika" (in Russian).

2. Cherni, D. I. (2016). Mathematical model of the flow in the shallow water area. Bulletin of Kharkiv National University of V.N. Karazina, (29), "Mat. fashion model. Informacion technology. Automation systems management”, 78-86 (in Russian).

3. Cherniy, D. I., Voskoboynik, V. A., \& Voskoboynik, O. A. (2016). Experimental and mathematical modeling of layered flows in a flat channel. In Naukovo-practical conference "Comp'yuterna gidromekhanika" (pp. 68-69). Kyiv, Ukraine: Institute of gidromekhaniki NAN Ukraine (in Russian).

4. Kordas, O., Gourjii, A., Nikiforovich, E. \& Cherniy, D. (2017). A study on mathematical short-term modelling of environmental pollutant transport by sea currents: The Lagrangian approach. Journal of Environmental Accounting and Management, 5(2), 87-104. doi: 10.5890/jeam.2017.06.002

5. Dovgy, S. A., Lifanov, I. K., \& Cherniy, D. I. (2016). The method of singular integral equations and computational technologies. Kyiv: Euston Publishing House (in Russian).

6. Dovgiy, S. O., Lyashko, S. I., \& Cherniy, D. I. (2017). Algorithms of Discrete Singularities Method of Computational Technologies. Cybernetics and System Analysis, (6), 147-159 (in Ukrainian). 
7. Cherniy, D., Dovgiy, S., \& Meleshko, V. (2013). The Vortex Model of a Viscid Wall's Layer. In IUTAM Symposium on "Vortex Dynamics: Formations, Structure and Function” (pp. 126-127). Fukuoka, Japan: Kyushu University School of Medicine.

8. Guan, D., Chiew, Y., Wei, M., \& Hsieh, S. (2019). Characterization of horseshoe vortex in a developing scour hole at a cylindrical bridge pier. Intern. J. Sedim. Res, 34(2), 118-124. 9. Koken, M. (2018). Coherent structures at different contraction ratios caused by two spillthrough abutments. J. Hydraul. Res., 56(3), 324-332.

10. R. Ettema G. , B.W., R., Constantinescu, G., \& Melville, B. W. (2017). Field complexity and design estimation of pier-scour depth: Sixty years since Laursen and Toch. J. Hydraul. Eng., 143(3) 03117006-1-14.

11. Baghbadorani, D. A., Ataie-Ashtiani, B., \& Beheshti, A. (2018). Prediction of currentinduced local scour around complex piers: Review, revisit, and integration. Coastal Eng., 133(3), 43-58.

12. Yang, Y., Qi, M., Li, J., \& Ma, X. (2018). Evolution of hydrodynamic characteristics with scour hole developing around a pile group. Water, 10(11), 1632-1-21.

13. Voskoboinick, A. A., Voskoboinick, A. V., \& Voskoboinick, V. A. (2008). Vizualizacija soprjazhennogo obtekanija gruppovoi mostovoi opory. Visnyk Donetskogo University, (1), ser. A: Pryrodnychi nauky, 219-227 (in Russian).

14. Voskoboinick, A. V., Voskoboinick, V. A., \& Voskoboinick, O. A. (2009). Osoblyvosti vykhrovogo rykhy u sprjazhenii techii mizh grypoju pal' tryrjadnoi mostovoi opory. Prykladna gidromekhanika, 11(2), 16-29 (in Ukrainian).

15. Voskoboinick, A. V., Voskoboinick, V. A., \& Voskoboinick, O. A. (2008). Sprjazhene obtikannja tryrjadnogo pal'nogo rostverku na plaskii poverkhni. Chastyna 1. Formuvannja pidkovopodibnykh vykhoriv. Prykladna gidromekhanika, 10(3), 28-39 (in Ukrainian).

16. Voskoboinick, A. V., Voskoboinick, V. A., \& Voskoboinick, O. A. (2008). Sprjazhene obtikannja tryrjadnogo pal'nogo rostverku na plaskii poverkhni. Chastyna 2. Prostorovochasovi korreljacii ta spektry. Prykladna gidromekhanika, 10(4), 13-25 (in Ukrainian).

17. Voskobijnyk, A. V., Voskoboinick, V. A., \& Voskoboinyk, O. A. (2016). Feature of the vortex and the jet flows around and inside the three-row pile group. In 8th International Conference on Scour and Erosion (ICSE 2016) (pp. 897-903). Oxford, UK.

18. Voskoboinick, V. A., Voskoboinick, A. V., Areshkovych, O. O., \& Voskoboinyk, O. A. (2016). Pressure fluctuations on the scour surface before prismatic pier. In 8th International Conference on Scour and Erosion (ICSE 2016) (pp. 905-910). Oxford, UK.

The article was received 13.02.2019 and was accepted after revision 05.03.2019

\section{Воскобійник Володимир Анатолійович}

доктор технічних наук, старший науковий співробітник, провідний науковий співробітник Інституту гідромеханіки НАН України

Адреса робоча: 03057 , Україна, м. Київ, вул. Желябова, 8/4

ORCID ID 0000-0003-2161-6923 e-mail: vlad.vsk@ gmail.com

\section{Воскобойник Олександр Анатолійович}

кандидат технічних наук, старший науковий співробітник Інституту гідромеханіки НАН України

Адреса робоча: 03057, Україна, м. Київ, вул. Желябова, 8/4

e-mail: alexandr.vsk@gmail.com

\section{Черній Дмитро Іванович}

кандидат фізико-математичних наук, доцент, провідний науковий співробітник Інституту телекомунікацій і глобального інформаційного простору НАН України

Адреса робоча: 03186, Україна, м. Київ-186, Чоколівський бульвар, 13

e-mail:Dmytro.Cherniy@gmail.com 